\title{
Dementia in patients with the acquired immunodeficiency syndrome
}

\section{DAVID A. BARON, MSEd, DO}

Central nervous system (CNS) manifestations are common in patients with the acquired immunodeficiency syndrome (AIDS). The most common CNS syndrome is a dementing illness referred to as the AIDS dementia complex, in which motor and cognitive changes may also be seen. Neurodiagnostic studies are fairly characteristic, though highly nonspecific. Dementia may precede overt manifestations of AIDS, and either an insidious or a fulminant course may be seen. Appropriate management of the patient with AIDS includes differentiating dementia from psychologic responses to the disease.

(Keywords: Acquired immunodeficiency syndrome, central nervous system, AIDS dementia complex, encephalitis)

The acquired immunodeficiency syndrome (AIDS) is due to infection by a retrovirus ${ }^{1,2}$ that is now termed the human immunodeficiency virus (HIV). ${ }^{3}$ Its clinical manifestations are protean. Symptomatic involvement of the central nervous system (CNS) occurs in at least $39 \%$ of all patients with AIDS; neoplasia and infection by viruses, fungi, and mycobacteria are common complications. ${ }^{4}$

The most frequent CNS manifestation of HIV infection is not a focal neurologic disease, but is instead a diffuse encephalitis. This disorder has been referred to as AIDS encephalopathy,${ }^{5}$ subacute encephalitis, ${ }^{6}$ subacute AIDS

Reprint requests to David A. Baron, MSEd, DO, Deputy Clinical Director, Intramural Research Program, National Institute of Mental Health, Bldg 10, Room 3N238, 9000 Rockville Pike, Bethesda, MD 20892. encephalitis, ${ }^{7}$ and the AIDS dementia complex (ADC). ${ }^{8}$ The reported incidence of ADC varies, affecting from $11 \% \%^{6}$ to $47 \%^{9}$ of AIDS patients seen. In August 1987, the Centers for Disease Control reported a revision of its case definition for AIDS, ${ }^{10}$ in which the presence of $\mathrm{ADC}$ in a person with laboratory evidence of HIV infection constitutes a diagnosis of AIDS.

\section{Manifestations}

The signs and symptoms of ADC have been described. ${ }^{6,8,11}$ Early manifestations involve cognitive, motor, and behavioral impairments. The most common early symptoms are cognitive and include forgetfulness, loss of concentration, and confusion. Motor symptoms may include loss of balance and leg weakness. Apathy and social withdrawal are behavioral changes frequently described, and a dysphoric mood is occasionally reported. Lethargy, malaise, and reduced sexual drive may also be present.

When first seen, a patient with ADC may have motor and verbal slowness as well as impaired cognition on mental status examination; normal findings on such examination, however, are not uncommon. Approximately half of the patients in whom ADC develops have abnormal findings on neurologic examination early in the course of ADC. Neurologic signs include ataxia, pyramidal tract signs, lower extremity weakness, and tremor.

In its later stages, $\mathrm{ADC}$ leaves the lives of patients utterly ravaged. The sine qua non of $\mathrm{ADC}$ is the eventual development of dementia, as defined by the Diagnostic and Statisti- 
cal Manual of Mental Diseases, third editionrevised $(D S M-I I I-R)^{12}$ criteria. The majority of these patients are bedridden and have severely limited intellectual and social capacities, although in some the ability to perform simple tasks is preserved. Psychomotor retardation is common. Patients sit awake with a wide-eyed stare - quiet, confused, and indifferent to their illness and surroundings.

An organic psychosis may occasionally be observed. Motor impairments are common in the later stages of ADC and may include ataxia, hypertonia, weakness (especially paraparesis), mycolonus, seizures (focal or generalized), and tremor. Many patients are incontinent. A peripheral neuropathy is far more likely to be found in an AIDS patient with ADC than in one without it.

Epstein and associates ${ }^{5}$ have reported a similar spectrum of changes in children with AIDS. Motor impairments, including ataxia, weakness, pyramidal tract signs, and seizures, predominated. They also observed apathy, and loss of intellectual and language abilities were also observed.

The presence of $\mathrm{ADC}$ is suggested by characteristic clinical features, yet it often may go undiagnosed..$^{13}$ No single test is diagnostic. On computed tomographic (CT) scans, generalized cerebral atrophy is nearly always seen, often with ventricular dilation. Attenuated white matter may also be seen in a minority of patients, and magnetic resonance imaging may be more sensitive than $\mathrm{CT}$ in detecting this abnormality. On examination of the CSF, a mild to moderate elevation of the protein level is often seen, which may rise during the clinical course in a subset of patients. These findings are occasionally accompanied by a mild mononuclear pleocytosis and, much less often, hypoglycorrhachia. In virtually all cases, electroencephalograms show an abnormality, often a mild, diffuse, bilateral, nonfocal slowing. . $-6,8,11,13^{-13}$

\section{Onset}

Although the onset of dementia in ADC is most often insidious, a significant number of patients experience an acute onset or acceleration. Navia and associates ${ }^{8}$ reported that once severely demented, the average $\mathrm{ADC}$ patient survives a mere 2 months. The total duration of dementia averages 4 months. ${ }^{8}$

Of the 112 patients with ADC seen by Navia and Price, ${ }^{13}$ one fourth had no manifestations of AIDS on initial examination; and full-blown AIDS did not subsequently develop in half of these asymptomatic patients, virtually all of whom were in groups at risk of AIDS and had documented HIV infection. When first seen, the majority of the 112 patients had the AIDSrelated complex (ARC), although nearly $25 \%$ were clinically well. The mean duration of dementia averaged 8 months. This observed duration may be attributable to recognition of dementia earlier in the course of these patients' illness and supports the contention that $\mathrm{ADC}$ is often the manifestation of an insidious process.

\section{Neuropathologic changes}

Several studies have documented the neuropathologic changes of ADC. In $90 \%$ of brains from patients with AIDS or ARC, de la Monte and associates ${ }^{14}$ identified a subacute encephalomyelitis, characterized by astrocytosis of white matter, gliosis of gray matter, microglial nodules, and small foci of necrosis in both the gray and white matter. Demyelination and axonal changes were also seen. Of the $50 \%$ of brains in which these changes were moderate to severe, $37 \%$ were from patients in whom dementia had been recognized. Similar changes, including slight myelin pallor, were reported by Levy and coworkers. ${ }^{4}$ Diffuse demyelination and pallor of white matter were among the findings reported by Nielsen and coworkers ${ }^{9}$ in all the brains they examined. The neuropathologic changes in patients with AIDS, as found in several series, are reviewed by Rhodes. ${ }^{7}$

Navia and colleagues ${ }^{15}$ examined the brains from 46 demented AIDS patients who had neither focal CNS disease nor sustained metabolic encephalopathy. Abnormalities were found predominantly in the white matter and in subcortical structures, with relative sparing of the cortex. The most common finding was diffuse pallor in the white matter. The finding most specific to $\mathrm{ADC}$ was the presence of multinucleated cells; patients whose brains contained 
these cells had a dementia of greater severity and duration.

Cummings and Benson ${ }^{16}$ have defined subcortical dementia on the basis of similarities in the dementia of several disorders, including Huntington's disease, progressive supranuclear palsy, and Parkinson's disease. Apathy, disorder of mood, impaired cognition, forgetfulness, motor deficits, and abnormalities of movement are common features. Navia and coworkers ${ }^{8}$ have pointed out that many of the clinical and pathologic features of $\mathrm{ADC}$ are consistent with its classification as a subcortical dementia.

The suspected cause of $\mathrm{ADC}$ is direct infection of the CNS by HIV owing to a tremendous amount of supporting evidence. A syndrome such as ADC has not been reported in other immunocompromised populations. Shaw and associates, ${ }^{17}$ using Southern blot analysis and in situ hybridization, were able to demonstrate the presence of HIV nucleic acid in five of 15 brains of patients with ADC. Ho and coworkers ${ }^{18}$ recovered HIV from the CNS of ten of 16 patients with ADC, but from none of 12 patients with no neurologic symptoms. Of the 11 brains from which HIV was recovered by de la Monte and colleagues, ${ }^{14}$ ten had the pathologic features of ADC. Using a monoclonal antibody, Pumarola-Sune and associates ${ }^{19}$ observed that viral distribution parallels neuropathologic abnormalities in $\mathrm{ADC}$. Although identification of the HIV protein in the brain was $100 \%$ specific for a clinical course that had included ADC, less that half of the brains from patients who had ADC were reactive for the HIV protein in this study. The authors suggested that the occurrence of brains testing negative for HIV protein from ADC patients might be accounted for by a defective infection with a limited viral gene transcription, or by an antigen expression that resembles that of visna virus, a sheep retrovirus.

\section{Psychologic deficits}

Given the significant frequency with which dementia and its earlier symptoms may precede the more overt manifestations of AIDS and ARC, ${ }^{13}$ the assessment of psychologic deficits has become increasingly important. The psy- chologic response to a diagnosis of AIDS involves medical, psychologic, and sociocultural factors.

Holland and Tross ${ }^{20}$ have outlined common features in patients' responses. Aspects of the disease that may precipitate distress include physical stigmata, compromise of health, alteration of sexual behavior, frequent hospitalization, loss of employment, reduced independence, witnessing of a friend in the terminal stages of AIDS, forced identification as a member of a group at risk, and discrimination. The previous level of psychologic adjustment and social support are important in determining how the psychologic sequelae of AIDS will be expressed for a given patient.

The psychological symptoms, including the emotional reaction to AIDS and its complications, may be difficult to differentiate from ADC. Anxiety and depression are two examples.

To a large degree, the symptoms of distress experienced by a patient with AIDS are similar to those seen in patients with terminal cancer. Symptoms of anxiety, including worry, fear, and hypochondriacal concerns, occur. Symptoms of depression, such as sadness, helplessness, worthlessness, social withdrawal, apathy, and psychomotor retardation, are commonly encountered.

The most common DSM-III- $R$ diagnoses observed by Dilley and colleagues ${ }^{21}$ in psychiatric consultation were adjustment disorder with depressed mood, major depression, or dysthymic disorder. Unfortunately, these findings may often go unrecognized. Perry and Tross, ${ }^{22}$ reviewing the charts of 52 patients with AIDS, found reference to neuropsychiatric symptoms appeared in $100 \%$ of the charts, with $83 \%$ of the patients reporting some form of depression. Nonetheless, psychiatric consultation was requested in only $19 \%$ of all cases. This finding is consistent with the observation ${ }^{13}$ that $\mathrm{ADC}$ often goes unrecognized.

It is therefore apparent that the presence of depressed mood, decreased memory, apathy, social withdrawal, and psychomotor retardation in a patient with AIDS may represent either a psychologic reaction to, or a neuropsychiatric manifestation of, the disease. Asympto- 
matic HIV infection of the CNS can occur. Neuropathologic changes of $\mathrm{ADC}$ may be found without antecedent dementia ${ }^{14,15}$; HIV infeetion of the CNS may occur without dementia ${ }^{18}$; and intra-blood-brain barrier synthesis of antiHIV immunoglobulin G (IgG) may occur without neurologic symptoms. ${ }^{23}$ Holland and Tross ${ }^{20}$ assert that diagnosis of ADC should be suspected in all high-risk patients who manifest any change in mentation or neurologic functioning.

\section{Management}

Perry and Tross ${ }^{22}$ have outlined the following measures for dealing with the neuropsychiatric complications of AIDS, including ADC, during medical hospitalization.

- Mental status should be documented, as with the Mini-Mental State examination. ${ }^{24}$

- Disorders of mood, thinking, or behavior should not be viewed presumptively as psychogenic until organic determinants have been ruled out.

- Pharmacologic intervention, including the use of neuroleptics in certain organic disorders, should be instituted as appropriate.

- Aftercare should be arranged as early as possible.

Faulstich ${ }^{25}$ recommends neuropsychiatric testing as a differentiating tool, suggesting that monitoring of mental status and cognitive deficits should become an integral part of the overall management of patients with AIDS. Benzodiazepines, stress-management, antidepressant therapy, and problem-solving procedures may all be of benefit to selected patients.

\section{Prognosis}

The prognosis for $\mathrm{ADC}$ continues to be grim; however, with treatable syndromes in the differential diagnosis, an accurate diagnosis should be pursued aggressively. Furthermore, palliative therapy is available. The virustatic drug zivudine (azidothymidine; AZT) has been shown to achieve excellent penetration of the blood-brain barrier ${ }^{26}$ and clinical effectiveness is now firmly established.

\section{Comment}

This article is intended as a broad-stroke over- view for the primary care physician. Since this article was originally written, new important developments have been made in effective treatment strategies for those afflicted with this devastating disease, and extensive research continues in this important clinical area.

1. Barre-Sinoussi F, Chermann JC, Rey F, et al: Isolation of a T-lymphotropic retrovirus from a patient at risk for acquired immune deficiency syndrome (AIDS). Science 1983;220:868870 .

2. Gallo RC, Salahuddin SZ, Popovic M, et al: Frequent detection and isolation of cytopathic retroviruses (HTLV-III) from patients with AIDS and at risk for AIDS. Science 1984;224:550502 .

3. Coffin J, Haase A, Levy JA, et al: Human immunodeficiency viruses. Science 1986;232:697.

4. Levy RM, Bredesen DE, Rosenblum ML: Neurological manifestations of the acquired immunodeficiency syndrome (AIDS): Experience at UCSF and review of the literature. J Neurosurg 1985;62:475-495.

5. Epstein LG, Sharer LR, Joshi VV, et al: Progressive encephalopathy in children with acquired immune deficiency syndrome. Ann Neurol 1985;17:488-496.

6. Snider WD, Simpson DM, Nielsen S, et al: Neurological complications of acquired immune deficiency syndrome: Analysis of 50 patients. Ann Neurol 1983;14:403-418.

7. Rhodes RH: Histopathology of the central nervous system in the acquired immunodeficiency syndrome. Hum Pathol 1987;18:636-643.

8. Navia BA, Jordan BD, Price RW: The AIDS dementia complex: I. Clinical features. Ann Neurol 1986;19:517-524.

9. Nielsen SL, Petito CK, Urmacher CD, et al: Subacute encephalitis in acquired immune deficiency syndrome: A postmortem study. Am J Clin Pathol 1984;82:678-682.

10. Centers for Disease Control: Revision of the CDC surveillance case definition for acquired immunodeficiency syndrome. MMWR 1987;36(1S):3S-15S.

11. Jordan BD, Navia BA, Petito CA, et al: Neurological syndromes complicating AIDS. Front Radiat Ther Oncol 1985;19:8287.

12. American Psychiatric Association, Committee on Nomenclature and Statistics: Diagnostic and Statistical Manual of Mental Disorders, ed 3-revised. Washington, DC, American Psychiatric Association, 1987.

13. Navia BA, Price RW: The acquired immunodeficiency syndrome dementia complex as the presenting or sole manifestation of human immunodeficiency virus infection. Arch Neurol 1987;44:65-69.

14. de la Monte SM, Ho DD, Schooley RT, et al: Subacute encephalomyelitis of AIDS and its relation to HTLV-III infection. Neurology 1987;37:562-569.

15. Navia BA, Cho E, Petito CK, et al: The AIDS dementia complex: II. Neuropathology. Ann Neurol 1986;19:525-535.

16. Cummings JL, Benson DF: Subcortical dementia. Arch Neurol 1984;41:874-879.

17. Shaw GM, Harper ME, Hahn BH, et al: HTLV-III infection in brains of children and adults with AIDS encephalopathy. Science 1985;227:177-182.

18. Ho DD, Rota TR, Schooley RT, et al: Isolation of HTLV-III from cerebrospinal fluid and neural tissues of patients with neu- 
rologic syndromes related to the acquired immunodeficiency syndrome. N Engl J Med 1985;313:1493-1497.

19. Pumarola-Sune T, Navia BA, Cordon-Cardo C, et al: HIV antigen in the brains of patients with the AIDS dementia complex. Ann Neurol 1987;21:490-506.

20. Holland JC, Tross S: The psychosocial and neuropsychiatric sequelae of the acquired immunodeficiency syndrome and related disorders. Ann Intern Med 1985;103:760-764.

21. Dilley JW, Ochitill HN, Perl M, et al: Findings in psychiatric consultations with patients with acquired immune deficiency syndrome. Am J Psychiatry 1985;142:82-86.

22. Perry SW, Tross S: Psychiatric problems of AIDS inpatients at the New York Hospital: Preliminary report. Pub Health Rep 1984;99:200-205.

23. Resnick L, diMarzo-Veronese F, Schupback J, et al: Intrablood-brain-barrier synthesis of HTLV-III-specific IgG in patients with neurologic symptoms associated with AIDS or AIDSrelated complex. $N$ Engl $J$ Med 1985;313:1498-1504.

24. Folstein MF, Folstein SE, McHugh PR: Mini-mental state: A practical method for grading the cognitive state of patients for the clinician. J Psychiatr Res 1976;12:189-198.

25. Faulstich ME: Acquired immune deficiency syndrome: an overview of central nervous system complications and neuropsychological sequelae. Int $J$ Neurosci 1986;30:249-254.

26. Klecker RW, Collins JM, Yarchoan R, et al: Plasma and cerebrospinal fluid pharmacokinetics of 3'-azido-3'-deoxythymidine: A novel pyrimidine analog with potential application for the treatment of patients with AIDS and related diseases. Clin Pharmacol Ther 1987;41:407-412. 


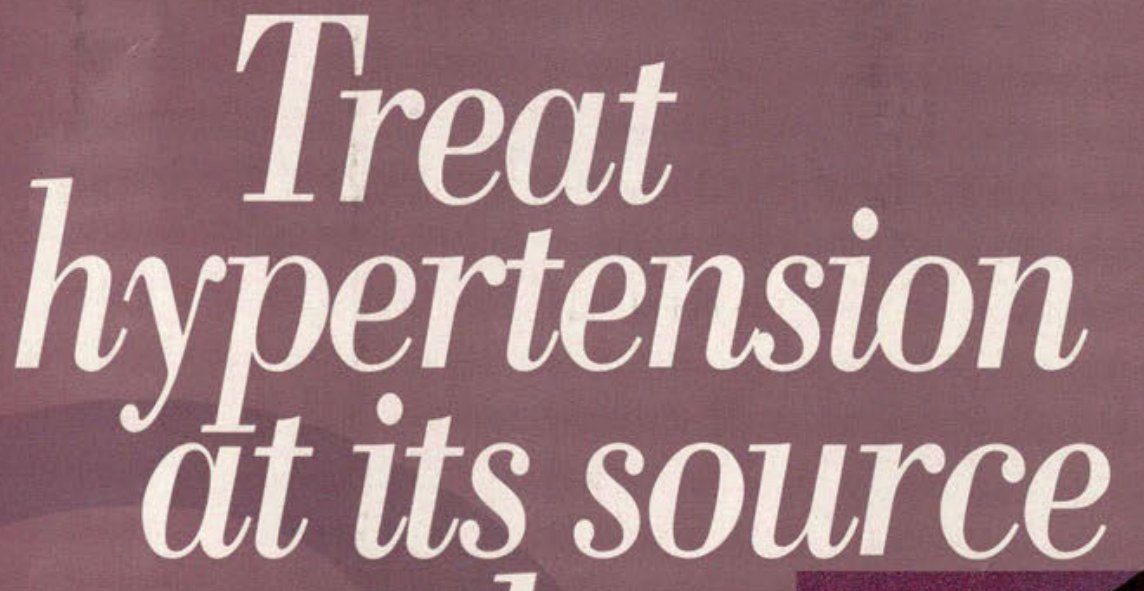

with...

ONCE-A-DAY

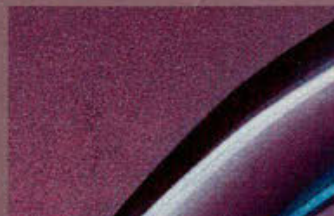

d.।

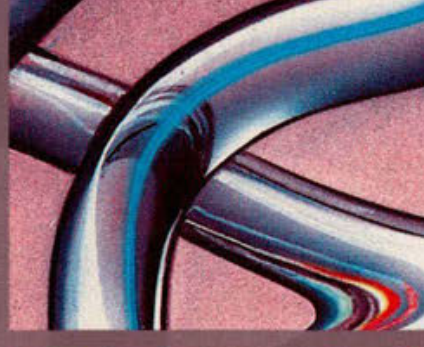





\section{CARDURA is effective first-line therapy for hypertension}

* lowers blood pressure regardless of age or race'

\& provides smooth 24-hour efficacy with once-a-day dosing ${ }^{2}$

it has minimal effect on glucose metabolism, insulin levels, ${ }^{3}$ renal function, electrolytes, ${ }^{2}$ and important selected parameters ${ }^{2}$

\& lowers blood pressure with small decreases in total and LDL cholesterol and a small increase in the $\mathrm{HDL} /$ total cholesterol ratio $^{2^{*}}$

¿ discontinuation rate of $2 \%$ in clinical trials - same as placebo ${ }^{2}$ CARDURA is well tolerated. In placebo-controlled studies, only three common side effects were reported more often than with placebo: dizziness, somnolence, and fatigue. These were generally mild and transient. Syncope has been reported, but rarely $(<1 \%)$.

ATCE-A-DAY

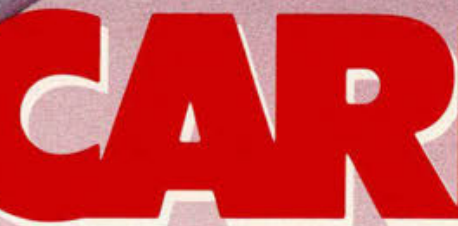
doxazosin mesylate) Treats hypertension at its source 
2. Convenient once-a-day dosage

Most responsive patients are controlled with one daily dose of 4 to $8 \mathbf{m g}^{2}$

- recommended initial dose is $1 \mathrm{mg}$, with dosage range of $1 \mathrm{mg}$ to $16 \mathrm{mg}$ per day.
1. Begin all patients with CARDURA $1 \mathrm{mg}$ once daily to minimize side effects. Evaluate supine and standing blood pressure. Prescribe

CARDURA 2 mg once daily,

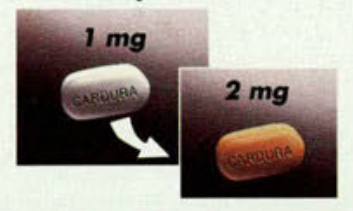
if necessary.
Evaluate for blood pressure control. Prescribe $4 \mathrm{mg}$ once daily, if necessary.

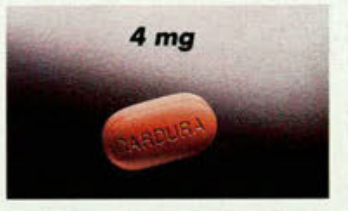

2. Evaluate for blood pressure control. Prescribe $8 \mathrm{mg}$ onc daily, if necessary. Maximum recommended dosage is $16 \mathrm{mg}$ once daily.

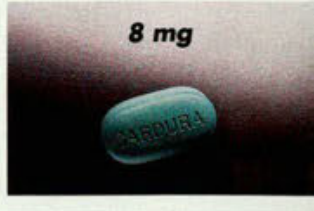

diziness, lightheadedness, or palpitations are bothersome they should be reported the physician, so that dose adjustment can be considered. Patients should also be told that drowsiness or somnolence can occur with doxazosin, requiring caution in people who must drive or operate heavy machinery.

Drug interactions:

Most (98\%) of plasma doxazosin is protein bound. In vitro data in human plasma indicate that CARDURA has no effect on protein binding of digoxin, wartarin, phenytoin or indomethacin. There is no information on the effect of other highty plasma protein bound drugs on doxarosin binding. CARDURA has been administered without any evidence of an adverse drug interaction to patients receiving thiazide diuretics, beta blocking agents, and nonsteroidal antireceiving thiazide dinte

Drug/Laboratory test interactions:

Cardiac Toxicity in Animals:

An increased incidence of myocardial necrosis or fibrosis was displayed by

Sprague-Dawley rats after 6 months of dietary administration at concentration

calculated to provide $80 \mathrm{mg}$ doxazosin/kg/day and atter 12 months of dietary

administration at concentrations calculated to provide $40 \mathrm{mg}$ doxazosin/kg/day

$60 \mathrm{~kg}$ ). There is no evidence that similar lesions occur in humans

Carcinogenesis, Mutagenesis and Impairment of Fertility:

Chronic dietary administration (up to 24 months) of doxazosin mesylate at maximally tolerated concentrations (highest dose $40 \mathrm{mg} / \mathrm{kg}$. about 150 times the maximum recommended human dose of $16 \mathrm{mg} / 60 \mathrm{~kg}$ ) revealed no evidence of carcinogenicity in rats. There was also no evidence of carcinogenicity in a similarly conducted study (up to 18 months of dietary administration) in mice. The mouse study, however, was compromised by the failure to use a maximally tolerated dose

Mutagenicity studies revealed no drug- or metabolite-related efflects at either chromosomal or subchromosomal levels

Studies in rats showed reduced fertility in males treated with doxazosin at oral doses of 20 (but not 5 or 10 ) $\mathrm{mg} / \mathrm{kg} /$ day, about 75 times the maximum

recommended human dose. This effect was reversible within two weeks of drug

withdrawal.

Pregnancy

Teratogenic Effects, Pregnancy Category B. Studies in rabbits and rats at

daily oral doses of up to 40 and $20 \mathrm{mg} / \mathrm{kg}$, respectively ( 150 and 75 times the

maximum recommended daily dose of the mg, assuming a patient weight of $60 \mathrm{~kg}$.

compromised by the tailure to use a maximally tolerated dose of doxazosin. There

are no adequate and well-controlled studies in pregnant women. Because animal

are no adequarte and well-controlled studies in pregnant women. Because ani

should be used during pregnancy only if clearly needed

Radioactivity was found to cross the placenta following oral administration of hadioacivity was lound to cross the

Nonteratogenic Eftects. In peri-postnatal studies in rats, postnatal development th maternal doses of 40 or $50 \mathrm{mg} / \mathrm{kg}$ day of dovazesin was delayed as evidenced by slower body weight gain and a slightly later appearance of anatomical teatures and reflexes.

Nursing Mothers

It is not known whether this drug is excreted in human milk. Because many drugs

are excreted in human milk, caution should be exercised when CARDURA is

administered to a nursing mother.

Pediatric Use

ADVEty and effectiveness in

CARDURA has been administered to approximately 4000 patients, of whom 1679 were included in the clinical development program. In that program, minor adverse effects were frequent, but led to discontinuation of treatment in only $7 \%$ of patients. In placebo-controlled studies adverse effects occurred in $49 \%$ and $40 \%$ of patients in the doxazosin and placebo groups, respectively, and led to discontinuation in 2 of patients in each group. The major reasons for discontinuation were postural effects (2\%), edema, malaise//atigue, and some heart rate disturbance, each about

$0.7 \%$ In controlled clinical trials directly comparing CARDURA to placebo there was no significant difference in the incidence of side effects, except for dizziness (including postural), weight gain, somnolence and fatigue/malaise. Postural effects and edema appeared to be dose related.

The prevalence rates presented below are based on combined data from placebocontrolled studies involving once dally administration of doxazosin at doses ranging from 1-16 mg. Table 1 summarizes those adverse experiences (possibly/probably related) reported for patients in these studies where the prevalence rate in the doxazosin group was at least $0.5 \%$ or where the reaction is of particular interesL

2. Impaired liver function:

CARDURA should be administered with caution to patients with evidence of impaired hepatic function or to patients receiving drugs known to influence hepatic experience with CARDURA in patients with these conditions.

3. Leukopenia/Neutropenia:

Analysis of hematologic data from patients receiving CARDURA in controlled Clinical trials showed that the mean WBC (N=474) and mean neutrophil counts (N-419) were decreased by $2.4 \%$ and $1.0 \%$ respectively, compared to placebo, a phenomenon seen with other alpha blocking drugs. A search through a data base of
2400 patients revealed 4 in which drug-related neutropenia could not be ruled out. Two had a single low value on the last day of treatment. Two had stable, nonprogressive neutrophil counts in the $1000 / \mathrm{mm}^{3}$ range over periods of 20 and 40 weeks. In cases where follow-up was available the WBCs and neutrophil coun returned to normal after discontinuation of CARDURA. No patients became Symptomatic as a result of the

Information for Patients:
Patients should be made aware of the possibility of syncopal and orthostatic symptoms, especially at the initiation of therapy, and urged to avoid driving or hazardous lasks for 24 hours atter the first dose, atter a dosage increase, and ather intercuption or therapg when treadment is resumed. They should be cautioned to avoid situations where injury could result snould syncope occur during initiation af doxazosint therapy. They should al so be advised of the need to sit or lie down when symploms of lowered blood pressure occur, although these symptoms are not

\begin{tabular}{|c|c|c|c|}
\hline \multicolumn{4}{|c|}{ TABLE 1: ADVERSE REACTIONS DURING PLACEBO CONTROLLED STUDIES } \\
\hline & & $\begin{array}{c}\text { DOXAZOSIN } \\
(\mathrm{N}=339)\end{array}$ & $\begin{array}{l}\text { PLACEBB } \\
(\mathbb{N}=336)\end{array}$ \\
\hline CARDIOVASCULAR & $\begin{array}{l}\text { Diziness } \\
\text { Vertigo } \\
\text { Postural Hypotension } \\
\text { Edema } \\
\text { Paipitation } \\
\text { Arnythmia } \\
\text { Hypotension } \\
\text { Tachycardia } \\
\text { Peripheral Ischemia } \\
\end{array}$ & $\begin{array}{l}19 \% \\
2 \% \\
0.3 \% \\
4 \% \\
2 \% \\
1 \% \\
1 \% \\
0.3 \% \\
0.3 \% \\
\end{array}$ & $\begin{array}{l}9 \% \\
1 \% \\
0 \% \\
3 \% \\
3 \% \\
0 \% \\
0 \% \\
1 \% \\
0 \% \\
\end{array}$ \\
\hline SKIN APPENDAGES & $\begin{array}{l}\text { Rash } \\
\text { Pruritus }\end{array}$ & $\begin{array}{l}1 \% \\
1 \% \\
\end{array}$ & $\begin{array}{l}1 \% \\
1 \% \\
\end{array}$ \\
\hline MUSCULOSKELETAL & $\begin{array}{l}\text { Arthralgia/Arthritis } \\
\text { Muscle Weakness } \\
\text { Myalgia }\end{array}$ & $\begin{array}{l}1 \% \\
1 \% \\
1 \% \\
\end{array}$ & $\begin{array}{l}0 \% \\
0 \% \\
0 \%\end{array}$ \\
\hline $\begin{array}{l}\text { CENTRAL \& } \\
\text { PERIPHERAL N.S. }\end{array}$ & $\begin{array}{l}\text { Headache } \\
\text { Paresthesia }\end{array}$ & $\begin{array}{r}14 \% \\
1 \%\end{array}$ & $\begin{array}{r}16 \% \\
1 \%\end{array}$ \\
\hline
\end{tabular}

DOXAZOSIN PLACE $(\mathrm{N}-33 \mathrm{3})$

\begin{tabular}{|c|c|c|}
\hline & $\begin{array}{l}\text { Kinetic Disorders } \\
\text { Ataxia } \\
\text { Hypertonia } \\
\text { Muscle Cramps }\end{array}$ & $\begin{array}{l}1 \% \\
1 \% \\
1 \% \\
1 \%\end{array}$ \\
\hline AUTONOMIC & $\begin{array}{l}\text { Mouth Dry } \\
\text { Flushing }\end{array}$ & $\begin{array}{l}2 \% \\
1 \% \\
\end{array}$ \\
\hline SPECIAL SENSES & $\begin{array}{l}\text { Vision Abnormal } \\
\text { Conjunctivitis/Eye Pain } \\
\text { Tinnitus }\end{array}$ & $\begin{array}{l}2 \% \\
1 \% \\
1 \% \\
\end{array}$ \\
\hline PSYCHIATRIC & $\begin{array}{l}\text { Somnolence } \\
\text { Nervousness } \\
\text { Depression } \\
\text { Insomnia } \\
\text { Sexual Dystunction }\end{array}$ & $\begin{array}{l}5 \% \\
2 \% \\
1 \% \\
1 \% \\
2 \% \\
\end{array}$ \\
\hline GASTROINTESTINAL & $\begin{array}{l}\text { Nausea } \\
\text { Diarnhea } \\
\text { Constipation } \\
\text { Dyspepsia } \\
\text { Flatulence } \\
\text { Abdominal Pain } \\
\text { Vomiting } \\
\end{array}$ & $\begin{array}{l}3 \% \\
2 \% \\
1 \% \\
1 \% \\
1 \% \\
0 \% \\
0 \% \\
\end{array}$ \\
\hline RESPIRATORY & $\begin{array}{l}\text { Rhinitis } \\
\text { Dyspnea } \\
\text { Epistaxis }\end{array}$ & $\begin{array}{l}3 \% \\
1 \% \\
1 \% \\
\end{array}$ \\
\hline URINARY & $\begin{array}{l}\text { Polyuria } \\
\text { Urinary Incontinence } \\
\text { Micturation Frequency }\end{array}$ & $\begin{array}{l}2 \% \\
1 \% \\
0 \%\end{array}$ \\
\hline GENERAL & $\begin{array}{l}\text { Fatigue/Malaise } \\
\text { Chest Pain } \\
\text { Asthenia } \\
\text { Face Edema } \\
\text { Pain }\end{array}$ & $\begin{array}{l}12 \% \\
2 \% \\
1 \% \\
1 \% \\
2 \%\end{array}$ \\
\hline
\end{tabular}

Additional adverse reactions have been reported, but these are, in general. distinguishable from symptoms that might have occurred in the absence of exposure to doxazosin. The following adverse reactions occurred with a frequ between $0.5 \%$ and $1 \%$ : syncope, hypoesthesia, increased sweating, agitation increased weight. The following additional adverse reactions were reported by $<0.5 \%$ of 3960 patients who received doxazosin in controlled or open, shortlong-term clinical studies, including international studies. Cardiovascular S. angina pectoris, myocardial infarction, cerebrovascular accident; Autonomic Nenvous System. pali or, Metabolic: thirst, gout, hypokalemia, Hernatopoietic lymphadenopatity, purpura, Reproductive System: breast pain; Skin Disord alopecia, dy skin, eczema, Central Nervous System: paresis, tremor, twitchi emotional lability, abnormal thinking, depersonalization; Special Senses: par

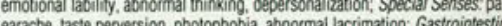
earache, laste perversion, pholophobia, abnomal lacrimation, Gastrointestim System. increased appetie, anorexia, lecal incontinence, gastroenteritis, Res

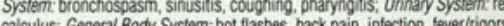
calculus, General Body system hot lashes, ba

Cocreased weight, intluenza-like symptoms. routine biocherical tests Noclinically relevant adverse effects were noted on serum polassium, serum glucose, uric acid, blood urea nitrogen, creatinine counts (See Precautions). counts (See Prec
OVERDOSAGE

The oral LD $D_{s 0}$ of doxazosin is greater than $1000 \mathrm{mg} / \mathrm{kg}$ in mice and rats. Th likely manitestation of overdosage would be hypotension, for which the usua treatment would be intravenous infusion of fluid. As doxazosin is highly prot bound, dialysis would not be indicated

DOSAGE AMD AOMINISTRATION

AUED. The initial dosage of CARDURA is hypertensive patients is $1 \mathrm{mg}$ given once daily. Depending on the individual patient's standing blood pressure response (based on measurements taken a hours postdose and 24 hours postdose), dosage may then be increased to 2 thereafter if necessary to $4 \mathrm{mg}, 8 \mathrm{mg}$ and $16 \mathrm{mg}$ to achieve the desired reduct blood pressure. Increases in dose beyond $4 \mathrm{mg}$ increase the likelinood of ex postural effects including syncope, postural dizziness/vertigo, postural hypo At a titrated dose of $16 \mathrm{mg}$ once daily the frequency of postural effects is abo compared to $3 \%$ for placebo.

HOW SUPPLIED

CARDURA (doxazosin mesylate) is available as colored tablets for oral administration. Each tablet contains doxazosin mesylate equivalent to $1 \mathrm{mg}$ $2 \mathrm{mg}$ (yellow), $4 \mathrm{mg}$ (orange) or $8 \mathrm{mg}$ (green) of the active constituent, doxa CARDURA TABLETS are available as $1 \mathrm{mg}$ (white), $2 \mathrm{mg}$ (yellow), $4 \mathrm{mg}$ ( and $8 \mathrm{mg}$ (green) scored tablets. Bottles of 100: $1 \mathrm{mg}$ (NDC 0049-2750-66),
(NDC 0049-2760-66), $4 \mathrm{mg}$ (NDC 0049-2770-66), $8 \mathrm{mg}$ (NDC 0049-2780-6 Recommended Storage: Store below $86^{\circ} \mathrm{F}\left(30^{\circ} \mathrm{C}\right.$.

CAUTION: Federal law prohibits dispensing without prescription, 65-4538-00-0

Issued Nov.
CARDURA has not been associated with any clinically significant changes

\section{Pfirer Roerig}

